\title{
openheart Predicting hospitalisation duration after transcatheter aortic valve implantation
}

Martijn S van Mourik, Leonie M E Geenen, Ronak Delewi, Esther M A Wiegerinck, Karel T Koch, Berto J Bouma, Jose P Henriques, Robbert J de Winter, Jan Baan Jr., M. Marije Vis

To cite: van Mourik MS, Geenen LME, Delewi R, et al. Predicting hospitalisation duration after

transcatheter aortic valve implantation. Open Heart 2017;4:e000549. doi:10.1136/ openhrt-2016-000549

Received 15 October 2016 Revised 6 January 2017 Accepted 10 January 2017

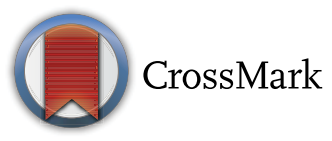

AMC Heart Center, Academic Medical Center, University of Amsterdam, Amsterdam, The Netherlands

Correspondence to Dr. M. Marije Vis; m.m.vis@ amc.nl

\begin{abstract}
Objective Transcatheter aortic valve implantation (TAVI) is widely used as an alternative to conventional surgical aortic valve replacement. The aim of this study was to identify preprocedural predictors of duration of length of stay (LoS) after transfemoral TAVI (TF-TAVI).

Methods We included all consecutive patients who underwent TF-TAVI at our centre between November 2010 and June 2013. Preprocedural, periprocedural and postprocedural variables were collected and evaluated to LoS. Linear regression was performed to find preprocedural predictors for total LoS.

Results The population consisted of 114 patients (mean age: $79.6 \pm 8.7,32.5 \%$ male). The median total LoS was 6.5 days (5-9 days). Multivariate analysis showed that the Metabolic Equivalent score (METs) $(\beta=-0.084, p=0.011)$ and diastolic blood pressure $(\beta=-0.011, p=0.016)$ independently contributed to the log-transformed LoS. Conclusion Multivariate linear regression showed that lower METs and lower diastolic blood pressure were associated with prolonged LoS. Understanding patients' physical functionality can improve logistical planning of hospital stay and selecting patients eligible for early discharge.
\end{abstract}

\section{INTRODUCTION}

Aortic valve replacement is indicated in case of severe aortic stenosis (AoS) or insufficiency. ${ }^{1}$ For patients with aortic valve stenosis, but at high risk for surgical aortic valve replacement, transcatheter aortic valve implantation (TAVI) is an appropriate alternative option. ${ }^{2}$ The transfemoral TAVI (TF-TAVI) approach is known to be the safest and therefore the most commonly used. ${ }^{34}$ Hospital length of stay (LoS) is associated with adverse events such as hospital-acquired infections and delirium. ${ }^{5}$ Postprocedural LoS may be influenced by various patient characteristics. Preprocedural risk assessment of LoS may yield several insights, such as appropriate patient information and individual organisational logistics. ${ }^{67}$ Additionally, some of the variables or patient characteristics may be optimised prior to the procedure to optimise the LoS. In this study we aim to elucidate preprocedural patient characteristics associated with LoS.

\section{KEY QUESTIONS}

What is already known about this subject?

- Transcatheter aortic valve implantation (TAVI) is widely used as an alternative to conventional surgical aortic valve replacement. The aim of this study was to identify preprocedural predictors of postprocedural length of hospital stay after transfemoral TAVI. Current studies are merely focused on outcomes in terms of mortality and symptom relief. The TAVI minimalist approach is gaining popularity and should also include a reduction of length of stay and be timely.

What does this study add?

- Our study describes our TAVI experience with the Edwards SAPIEN XT valve and preprocedural predictors for the duration of length of stay. Adding this knowledge to current literature allows better patient planning and selection of patients for early discharge. Furthermore it allows international comparison and finding best practices.

How might this impact on clinical practice?

- In the upcoming years patient-tailored medicine is coming into practice and patient-tailored plans for admission and procedure are made. This study might help clinicians decide on forehand which patients can have an early discharge and allows them more patient-specific planning.

\section{METHODS}

\section{Patient population and procedure}

This is a single-centre observational study with 114 consecutive patients undergoing TF-TAVI procedure between November 2010 and June 2013. All patients with severe symptomatic aortic valve stenosis were discussed by a multidisciplinary heart team and scheduled for a TF-TAVI procedure. TAVI procedures were performed according to standard techniques $^{8}$ using the balloon expandable Edwards SAPIEN XT valve, in sizes of $23 \mathrm{~mm}$, $26 \mathrm{~mm}$ and $29 \mathrm{~mm}$. General anaesthesia was avoided, allowing immediate recognition of periprocedural complications such as a cerebrovascular accident, and possibly reducing the occurrence of delirium post procedure. ${ }^{9}$ 


\section{Data collection and definitions}

Data were collected retrospectively in a dedicated database and contained preprocedural, periprocedural and postprocedural variables. Preprocedural variables included demographic details that include medical history, symptoms, medication, blood pressure, laboratory values, ECG, transthoracic echocardiogram (TTE) and CT scan.

Standard surgical risk assessment was performed using the Society of Thoracic Surgeons (STS) score and the EuroSCORE (European System for Cardiac Operative Risk Evaluation). ${ }^{10} 11$ The Metabolic Equivalent score (METs) was measured using the Duke Activity Status Index and was used as an estimation of a patient's functionality. ${ }^{12}$

Frailty was assessed by the Canadian Study of Health and Aging Clinical Frailty Score ${ }^{13}$ by means of the preoperative assessment by the anaesthesiology preprocedural screening regarding (non)instrumental activities and patient-reported daily life dependency. Medication before, during and after the procedure was also captured in our database. Preprocedural anticoagulants were categorised into five groups: (1) single antiplatelet drug, (2) dual antiplatelet therapy, (3) single oral anticoagulant, (4) single oral anticoagulant plus single antiplatelet drug or (5) single oral anticoagulant plus dual antiplatelet therapy. New oral anticoagulants and low-molecular weight heparin were labelled as oral anticoagulant.

Renal function, in terms of an estimated glomerular filtration rate (eGFR), was calculated using the modification of diet in renal disease (MDRD) formula. ${ }^{14}$

Preprocedural ECG assessment contained PQ time, QRS duration and QTc time.

Preprocedural TTE assessment encloses haemodynamic parameters, ejection fraction $(\mathrm{EF} \%)$, other valve insufficiencies and systolic pulmonary artery pressure. Periprocedural variables included the duration of the procedure, selected valve size, amount of contrast media used and periprocedural success. Periprocedural success was defined as implantation of a single aortic valve in the correct position without any cardiovascular events or valve dysfunction within the first 72 hours.

Procedural time was calculated as the time between the patient's arrival and discharge from operating room. All complications were analysed according to the Valve Academic Research Consortium (VARC) definitions. ${ }^{15}$ VARC two-criteria end points could not be used for this study as patient postprocedural urine output is not routinely measured, excluding the Acute Kidney Injury Network system and allowing only for the modified RIFLE (Risk, Injury, Failure, Loss of function, and End-stage kidney disease) classification. ${ }^{16}$ In addition to the VARC criteria, delirium, the need for a new pacemaker implantation and infections with a need for antibiotics were included as complications.
The hospital LoS was recorded as the total number of days between the TF-TAVI and the release of the patient from our centre.

\section{Statistical analysis}

Values are reported as mean $\pm \mathrm{SD}$ or median and IQR (IQR: 25th to 75th percentile) for continuous variables and as frequency with percentage for categorical variables. One-way analysis of variance and $\chi^{2}$ test for trends were used to compare the differences between groups of continuous and categorical variables, respectively. Group medians were compared using the Kruskal-Wallis test where appropriate. LoS was divided into three categories: (1) short stay (SS-LoS, 1-5 days), (2) medium stay (MS-LoS, 6-8 days) and (3) long stay (LS-LoS, 9+ days).

Covariates of interest as predictors of LoS were investigated using multivariable linear regression. Baseline variables that were significant at $p \leq 0.10$ on univariate analysis were entered into a multivariate model. All statistical tests were two-sided, and values of $\mathrm{p} \leq 0.05$ were considered statistically significant. Statistical analysis was performed using SPSS V.22 for Windows (IBM Corp, New York, USA).

LoS was log-transformed to normalise the distribution prior to linear regression analysis.

\section{RESULTS}

A total of 115 underwent TF-TAVI with the Edwards SAPIEN XT bioprosthesis between November 2010 and June 2013 at our centre. One patient died within hospital admission after developing acute kidney failure and was therefore excluded from the analysis, resulting in a study cohort of 114 patients. Baseline characteristics are shown in table 1 . The average age was $79.6( \pm 8.7)$ years and $32.5 \%$ were male $(\mathrm{n}=37)$. Most patients had an American Society of Anesthesiologists score of III or IV $(n=96,86.5 \%)$. Local anaesthesia was used in $98 \%(\mathrm{n}=112)$ of the cases.

Figure 1 is a graphic representation of the hospital routing of the study cohort.

The median total LoS was 6.5 days (IQR 5-9 days). The median LoS at the cardiac care unit was 1 day (IQR 1-1). Five patients were admitted at the intensive care unit, with a median of 2 days (IQR 1-7 days.)

\section{Preprocedural variables}

Preprocedural characteristics per grouped LoS are presented in table 2. There was a significant difference between LoS groups in age $(\mathrm{p}=0.004)$, STS-Risk of Procedural Mortality (STS-PROM) $(\mathrm{p}=0.007)$, Clinical Frailty Score $(p=0.043)$, METs $(p=0.004)$, diastolic blood pressure $(\mathrm{p}=0.023)$, N-terminal prohormone brain natriuretic peptide $(\mathrm{p}=0.038)$ and minimal diameter of the right iliac artery $(\mathrm{p}=0.026)$. A graphical representation of STS, EuroSCORE, METs and atrial fibrillation (AF) in the grouped LoS is shown in figure 2.

Univariate and subsequent multivariate analyses showed that there was a significant association with LoS for STS score $(p<0.001)$, baseline diastolic blood pressure $(\mathrm{p}=0.013)$ and METs $(\mathrm{p}=0.003)$. 


\begin{tabular}{|c|c|}
\hline & $\begin{array}{l}\text { Total } \\
\text { population } \\
(\mathrm{N}=114)\end{array}$ \\
\hline Age (years) & $79.6 \pm 8.7$ \\
\hline Male, $n(\%)$ & $37(32.5)$ \\
\hline Body surface area $\left(\mathrm{m}^{2}\right)$ & $1.88 \pm 0.21$ \\
\hline NYHA angina pectoris $\geq \mathrm{III}, \mathrm{n}(\%)$ & $11(9.6)$ \\
\hline NYHA dyspnoea $\geq$ III, $n(\%)$ & 39 (34.2) \\
\hline EuroSCORE 1 & $17.6 \pm 11.4$ \\
\hline Society of Thoracic Surgeons score & $6.6 \pm 5.6$ \\
\hline Estimated CSHA Clinical Frailty Score & $4.9 \pm 0.5$ \\
\hline \multicolumn{2}{|c|}{$\begin{array}{l}\text { ASA physical status classification system score } \\
(\mathrm{N}=111)\end{array}$} \\
\hline ASA I-II,n (\%) & $15(13.5)$ \\
\hline ASA III-IV,n (\%) & $96(86.5)$ \\
\hline Metabolic Equivalent score & $4(3-6)$ \\
\hline \multicolumn{2}{|l|}{ Risk factors } \\
\hline Diabetes mellitus, $\mathrm{n}(\%)$ & $30(26.3)$ \\
\hline Hypertension,n (\%) & $74(64.9)$ \\
\hline Hyperlipidaemia, n (\%) & $41(36.0)$ \\
\hline Positive family history, $\mathrm{n}(\%)$ & $9(7.9)$ \\
\hline \multicolumn{2}{|l|}{ Medical history } \\
\hline $\mathrm{PCl}, \mathrm{n}(\%)$ & $29(25.4)$ \\
\hline CABG, n (\%) & $11(9.6)$ \\
\hline Pacemaker/ICD, n (\%) & $12(10.5)$ \\
\hline Coronary artery disease, $\mathrm{n}(\%)$ & $48(42.1)$ \\
\hline Myocardial infarction, n (\%) & $15(13.2)$ \\
\hline Decompensated heart failure, $\mathrm{n}(\%)$ & $36(31.6)$ \\
\hline Kidney failure, $\mathrm{n}(\%)$ & $37(32.5)$ \\
\hline Peripheral vascular disease, n (\%) & $16(14.0)$ \\
\hline CVA, n (\%) & $7(6.1)$ \\
\hline TIA, n (\%) & $23(20.2)$ \\
\hline Chronic lung disease, $\mathrm{n}(\%)$ & $28(24.6)$ \\
\hline Liver cirrhosis, n (\%) & $1(0.9)$ \\
\hline \multicolumn{2}{|l|}{ Medication } \\
\hline Anticoagulant use, $\mathrm{n}(\%)$ & 90 (78.9) \\
\hline ACE inhibitor, $n(\%)$ & 37 (32.5) \\
\hline Beta-blocker, n (\%) & $62(54.4)$ \\
\hline Diuretic, n (\%) & $77(67.5)$ \\
\hline Metformin, n (\%) & $20(17.5)$ \\
\hline Statins, n (\%) & $63(55.3)$ \\
\hline
\end{tabular}

Numbers given as mean \pm SD or, if not normally distributed, as median \pm IQR.

ASA, American Society of Anesthesiologists; CABG, coronary artery bypass grafting; CSHA, Canadian Study of Health and Aging; CVA, cerebrovascular accident; EuroSCORE, European System for Cardiac Operative Risk Evaluation; ICD, implantable cardioverter defibrillator; NYHA, New York Heart Association; $\mathrm{PCl}$, percutaneous coronary intervention; TIA, transient ischaemic attack.

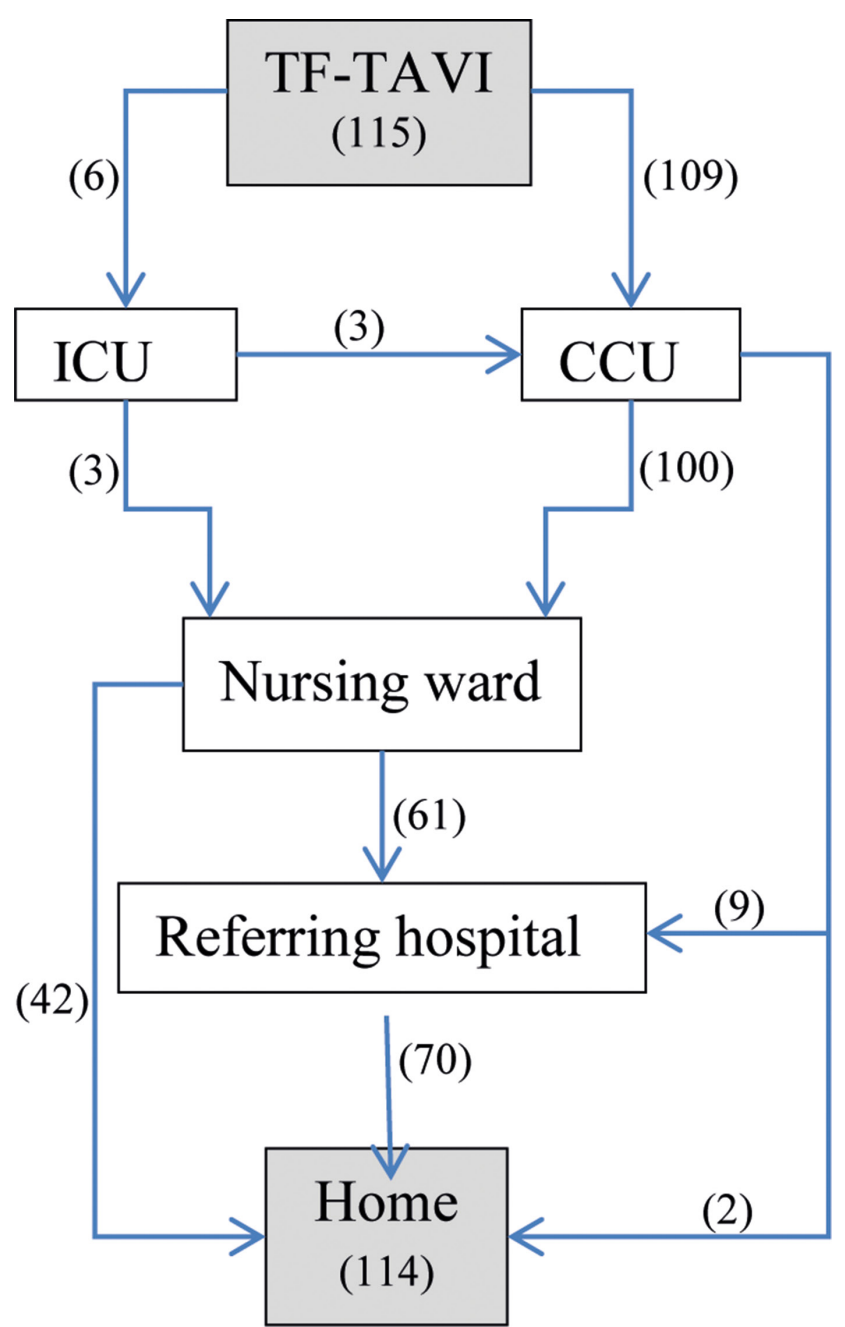

Figure 1 Procedural flow chart. TF-TAVI, transfemoral transcatheter aortic valve implantation; ICU, intensive care unit; CCU, cardiac care unit.

Univariate analysis on preprocedural variables (table 3) showed that STS score $(\beta=0.037, \mathrm{p}<0.001)$, baseline diastolic blood pressure $(\beta=-0.010, p=0.013)$, METs $(\beta=-0.086, p=0.003)$ and atrial fibrillation $(\beta=0.277$, $\mathrm{p}=0.041$ ) are associated with LoS.

ECG characteristics such as QRS duration, QT time and conduction disorders (left bundle branch block (LBBB), right bundle branch block (RBBB), intraventricular conduction disorders (IVCD), atrioventricular block (AVB)) did not show a significant association with LoS.

\section{Periprocedural variables}

As expected, complications were related to a longer LoS. Periprocedural complications are shown in table 4 . The median LoS is described for the various complications. A higher LoS can be expected after a periprocedural myocardial infarction, a major bleeding, acute kidney injury, minor vascular complication and hospital-acquired infection.

The difference between removing and remaining the temporary external pacemaker wire before 
Table 2 Preprocedural characteristics per grouped LoS

\begin{tabular}{|c|c|c|c|c|}
\hline & Short stay $(n=42)$ & $\begin{array}{l}\text { Medium stay } \\
(n=43)\end{array}$ & Long stay $(n=29)$ & p Value grouped LoS \\
\hline Age (years) & $76.1 \pm 11.1$ & $82.0 \pm 5.7$ & $80.9 \pm 6.8$ & 0.004 \\
\hline EuroSCORE 1 & $15.2 \pm 10.3$ & $17.9 \pm 12.5$ & $20.5 \pm 11.0$ & 0.151 \\
\hline STS-PROM & $4.5 \pm 3.1$ & $7.4 \pm 5.9$ & $8.4 \pm 7.1$ & 0.007 \\
\hline Previous CVA, n (\%) & $3(7.1)$ & $4(9.3)$ & $0(0)$ & 0.257 \\
\hline Previous chronic lung disease, $\mathrm{n}(\%)$ & $12(28.6)$ & $9(20.9)$ & $7(24.1)$ & 0.714 \\
\hline Diabetes, n (\%) & $13(31.0)$ & $9(20.9)$ & $8(27.6)$ & 0.568 \\
\hline Diastolic pressure (mm Hg) & $70.6 \pm 15.8$ & $68.0 \pm 14.4$ & $60.7 \pm 13.9$ & 0.023 \\
\hline Atrial fibrillation, n (\%) & $5(11.9)$ & $12(27.9)$ & $11(37.9)$ & 0.164 \\
\hline$P Q$ time $(\mathrm{ms})$ & $168 \pm 37$ & $172 \pm 60$ & $192 \pm 48$ & 0.825 \\
\hline QTc time (ms) & $433 \pm 47$ & $424 \pm 44$ & $445 \pm 47$ & 0.457 \\
\hline QRS time (ms) & $102 \pm 28$ & $92 \pm 26$ & $99 \pm 18$ & 0.806 \\
\hline Conduction disorder, n (\%) & $13(31.0)$ & $17(39.5)$ & $15(51.7)$ & 0.100 \\
\hline \multicolumn{5}{|l|}{ Echocardiogram } \\
\hline Mean gradient $(\mathrm{mm} \mathrm{Hg})$ & $46 \pm 22$ & $39 \pm 19$ & $44 \pm 26$ & 0.833 \\
\hline Aortic valve area $\left(\mathrm{cm}^{2}\right)$ & $0.78 \pm 0.23$ & $0.79 \pm 0.22$ & $0.74 \pm 0.30$ & 0.697 \\
\hline Haemoglobin & $8.0 \pm 1.1$ & $7.7 \pm 1.1$ & $7.6 \pm 0.8$ & 0.349 \\
\hline Haematocrit & $0.39 \pm 0.04$ & $0.38 \pm 0.05$ & $0.37 \pm 0.05$ & 0.300 \\
\hline INR & $1.02(0.99-1.18)$ & $0.99(0.97-1.16)$ & $1.06(0.99-1.15)$ & 0.575 \\
\hline Creatine & $97 \pm 63$ & $102 \pm 70$ & $100 \pm 47$ & 0.944 \\
\hline eGFR (MDRD) (mL/min/1.73 m²) & $70.0 \pm 24.7$ & $64.1 \pm 24.5$ & $60.6 \pm 11.8$ & 0.243 \\
\hline NT-proBNP & 1001 (618-2233) & 1512 (823-3040) & 1869 (1011-4139) & 0.038 \\
\hline \multicolumn{5}{|l|}{ CT parameters } \\
\hline Annulus diameter (mm) & $23.8 \pm 2.1$ & $23.7 \pm 1.5$ & $22.6 \pm 2.2$ & 0.161 \\
\hline Minimal diameter iliac R (mm) & $7.9 \pm 1.3$ & $7.8 \pm 1.3$ & $6.9 \pm 1.4$ & 0.026 \\
\hline Minimal diameter iliac $\mathrm{L}(\mathrm{mm})$ & $7.9 \pm 1.5$ & $7.9 \pm 1.1$ & $7.2 \pm 1.7$ & 0.230 \\
\hline
\end{tabular}

CVA, cerebrovascular accident; EF, ejection fraction; eGFR, estimated glomerular filtration rate; EuroSCORE, European System for Cardiac Risk Evaluation; INR, international normalised ratio; LoS, length of stay; LVF, left ventricular function; MDRD, modification of diet in renal disease; METs, Metabolic Equivalent score; NT-proBNP, N-terminal prohormone brain natriuretic peptide; STS-PROM, Society of Thoracic Surgeons-Risk of Procedural Mortality.

leaving the cathlab did not differ significantly between the LoS groups $(\mathrm{p}=0.419)$. The implantation of a permanent pacemaker did not lead to a longer median LoS.

Outcomes in terms of mortality are described in table 5.

\section{DISCUSSION}

In this retrospective study we found two predictors of post-TF-TAVI LoS. In a multivariate model, only diastolic blood pressure (negative association) and METs remained significant. 

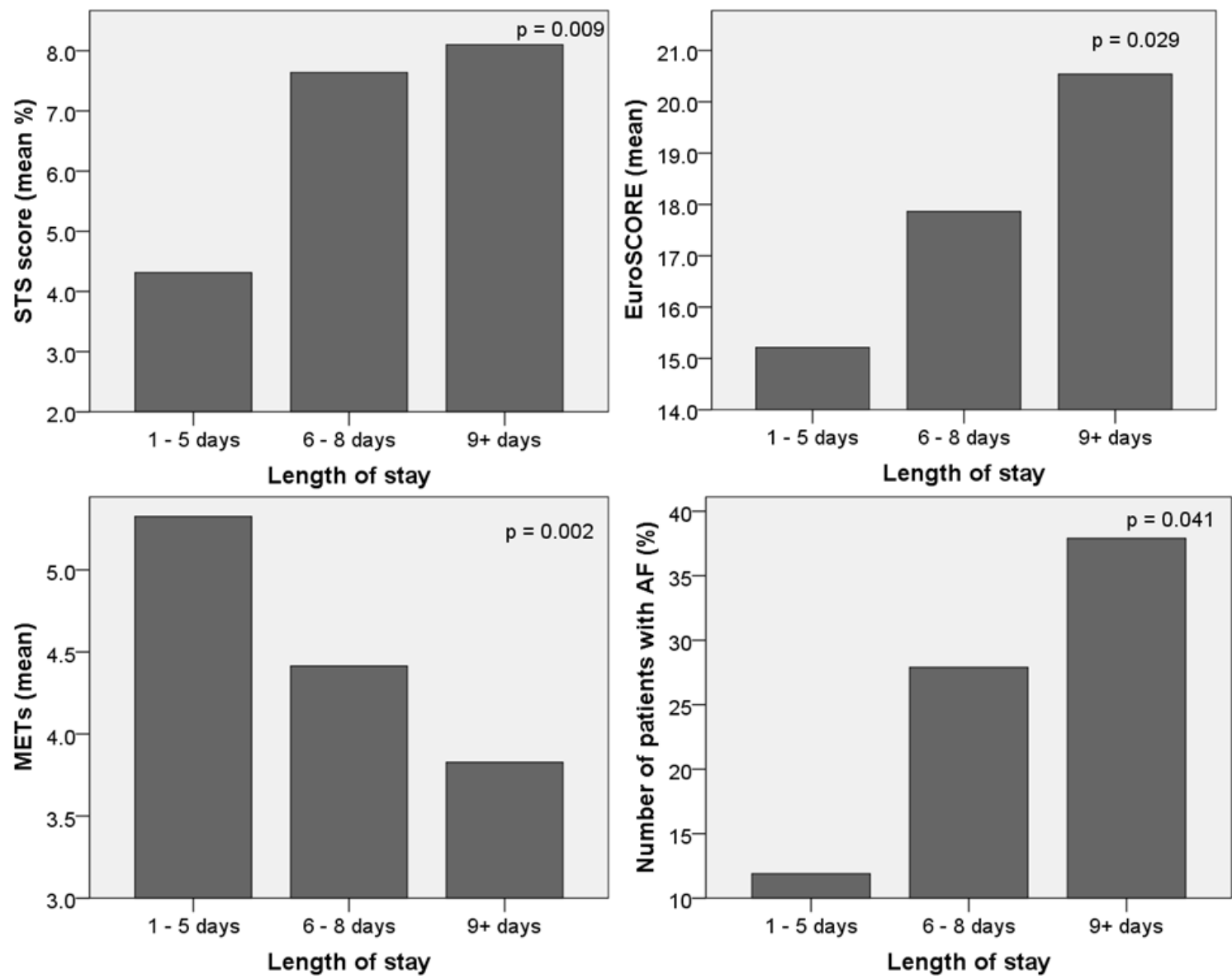

Figure 2 Figures showing the significant correlations between increased length of stay and increased STS scores, increased EuroSCORE, higher METs and pre-existent AF. AF, atrial fibrillation; EuroSCORE, European System for Cardiac Operative Risk Evaluation; METs, Metabolic Equivalent score; STS, Society of Thoracic Surgeons.

Table 3 Univariate and multivariate linear regression analyses: variables of table 2 showing a significance of $p<0.10$ were taken in the multivariate model

\begin{tabular}{|c|c|c|c|c|}
\hline & \multicolumn{2}{|c|}{ Univariate } & \multicolumn{2}{|c|}{ Multivariate } \\
\hline & Beta & $\mathrm{p}$ Value & Beta & $p$ Value \\
\hline Age (years) & 0.013 & 0.054 & & \\
\hline EurOSCORE 1 logistic & 0.011 & 0.029 & & \\
\hline STS & 0.037 & $<0.001$ & & \\
\hline METs & -0.086 & 0.003 & -0.084 & 0.011 \\
\hline Diastolic pressure $(\mathrm{mm} \mathrm{Hg})$ & -0.010 & 0.013 & -0.011 & 0.016 \\
\hline Atrial fibrillation & 0.277 & 0.041 & & \\
\hline Mitral regurgitation (II-IV) & 0.116 & 0.056 & & \\
\hline Minimal right iliac diameter & -0.109 & 0.012 & & \\
\hline \multicolumn{5}{|l|}{ Laboratory } \\
\hline Haemoglobin & -0.111 & 0.055 & & \\
\hline eGFR (MDRD) (mL/min/1.73 m²) & -0.004 & 0.077 & & \\
\hline NT-proBNP & 0.00006 & 0.054 & & \\
\hline
\end{tabular}

Length of stay is log-transformed to normalise the distribution.

eGFR, estimated glomerular filtration rate; EuroSCORE, European System for Cardiac Operative Risk Evaluation; MDRD, modification of diet in renal disease; METs, metabolic equivalent score; NT-proBNP, N-terminal prohormone brain natriuretic peptide; STS, Society of Thoracic Surgeons. 
Table 4 Postprocedural complications and their correlation with the total length of stay in days

\begin{tabular}{|c|c|c|}
\hline Complication & $\begin{array}{l}\text { No of patients } \\
(\mathrm{N}=114), \mathrm{n}(\%)\end{array}$ & $\begin{array}{l}\text { Median } \\
\text { days (IQR) }\end{array}$ \\
\hline Overall & 114 & $6.5(5-9)$ \\
\hline No complications & $52(45.6)$ & $6(4-8)$ \\
\hline $\begin{array}{l}\text { Temporary pacemaker wire not } \\
\text { removed during procedure }\end{array}$ & $56(49.1)$ & $6.5(5-11.75)$ \\
\hline \multicolumn{3}{|l|}{ Complications } \\
\hline $\begin{array}{l}\text { Periprocedural myocardial } \\
\text { infarction }\end{array}$ & $2(1.7)$ & $13.50(5-22)$ \\
\hline $\begin{array}{l}\text { Spontaneous myocardial } \\
\text { infarction }\end{array}$ & 0 & - \\
\hline TIA & 0 & - \\
\hline Minor stroke & $2(1.7)$ & $6.50(5-8)$ \\
\hline Major stroke & 0 & - \\
\hline Life-threatening bleeding & 0 & - \\
\hline Major bleeding & $2(1.8)$ & $17(6-28)$ \\
\hline Minor bleeding & $22(19.3)$ & $6(4.5-11.5)$ \\
\hline AKI stage I & $11(9.6)$ & $12(7-22)$ \\
\hline AKI stage II & $2(1.7)$ & $13.50(5-22)$ \\
\hline AKI stage III & 0 & - \\
\hline Major vascular complications & $0(0.0)$ & - \\
\hline Minor vascular complications & $20(17.5)$ & $7(5-11)$ \\
\hline Hospital-related infection & $9(7.8)$ & $8(6.5-17.5)$ \\
\hline Pacemaker implantation & $5(4.4)$ & $6.5(4.5-46.75)$ \\
\hline Delirium & $5(4.4)$ & $7(4-25)$ \\
\hline
\end{tabular}

AKI, acute kidney injury; TIA, transient ischaemic attack; VARC, Valve Academic Research Consortium.

\section{Risk scores}

In agreement with O'Brien $e t a l^{10}$ and Toumpoulis $e t a l^{11}$ an increase in STS-PROM score and EuroSCORE, respectively, was significantly associated with LoS. For the TAVI population the EuroSCORE is mainly used to predict operative mortality, however the Toumpoulis et al study also showed in a total cohort of 5051 cardiac surgery patients (of which 285 were aortic valve surgery patients) the correlation between the EuroSCORE and an LoS of $\geq 12$ days. In our cohort we did not find a significant relation between EuroSCORE and LoS, whereas STS score was significantly different. However, there was a trend of higher risk scores in the longer LoS groups.

Both the STS score and EuroSCORE are primarily made up of components that cannot be altered or

Table 5 Outcomes for study cohort

\begin{tabular}{ll}
\hline Mortality & $\begin{array}{l}\text { No of patients } \\
\text { (N=114) }\end{array}$ \\
\hline 30-Day cardiovascular mortality & $1(0.9 \%)$ \\
All-cause mortality 6 months & $7(6.1 \%)$ \\
All-cause mortality 1 year & $10(8.8 \%)$ \\
All-cause mortality 3 years & $29(25.4 \%)$ \\
\hline
\end{tabular}

optimised prior to the procedure, therefore acting solely as predictor, and not as an opportunity to decrease the LoS.

As the STS-PROM showed a greater significance with $\mathrm{LoS}$, it would be advisable to use this score when looking to predict LoS. In a study by Arangalage $e t a l^{17}$ EuroSCORE II was shown to be more similar to the STS-PROM score than the original EuroSCORE.

\section{Frailty}

The significance between METs and the trend with the estimated Clinical Frailty Score show that patients' disabilities, physical functioning and social network play a role in LoS. The estimated Clinical Frailty Score puts its emphasis more on being able to independently complete activities of daily living (ADL) or instrumental ADL, whereas METs looks specifically at the amount of energy used to complete these tasks. The Duke activity status index, which was used to estimate the METs, does reflect the level of physical functioning. Both these scores, however, are subjectively determined and therefore both only serve as an indication for patients' capacities. If medical urgency allows, actions to possibly improve METs or Clinical Frailty Score, such as improving strength and balance using physical therapy, could be offered prior to the procedure if patients' symptoms allow it. A parallel path would be to look into making alterations at home to improve possibilities of mobility and functionality at home, thereby making it possible for patients to further recover at home, rather than in the hospital. If in further research these variables are proven to shorten LoS, a physiotherapist or specialised nurse may be indicated as an important addition to the heart team discussions and planning for patients. As this would still be a subjective approach to predicting LoS, an altered validated frailty risk score should be developed to objectify the frailty and risk of patients prior to the procedure. As the STS score only looks at the chronological age of patients, an incorporation of the biological age might be beneficial. ${ }^{18}$

Age itself was not a predictor for LoS in the linear regression model. This might be that calendar age itself does not reflect the level of independence and level of physical activity, which is reflected by METs.

\section{Kidney function}

The influence of the kidney function on LoS has also been made apparent by means of eGFR. Furthermore creatine levels show a trend with LoS.

As kidney function seems to be a key predictor, it may be advisable to standardly use the newer CKD-EPI (Chronic Kidney Disease Epidemiology Collaboration) formula instead of the MDRD in the everyday clinical setting. This formula uses the same four variables as the MDRD formula (creatine level, age, gender and race) but uses a formula that has been shown to be more accurate in estimating the glomerular filtration rate (GFR), especially at higher GFRs. ${ }^{19}$ 
A common aetiology of a decreased kidney function is likely to be multifactorial with the populations' increased biological age, atherosclerosis, hypertension and medication usage. In this study the age of patients showed a trend with a higher LoS, which corresponds with many other studies, such as by Malaisrie $e t a .^{20}$

\section{Medication}

Preprocedural anticoagulant use was stopped prior to TAVI except for acetylsalicylic acid and/or P2Y12 inhibitors. The categorised combinations of preprocedural anticoagulant medication were significant with the total $\mathrm{LoS}$; however, it was not significant with any individual complications that would be suspected from anticoagulant use.

Chronic diuretic use was the only preprocedural medication that had a trend with LoS.

\section{Cardiac factors}

Extra emphasis on the management of AF pharmaceutically prior to the procedure may be an option to decrease LoS, ss 25 patients with AF were found to be using betablockers, despite its relative contraindication in significant AoS. Further research is needed to improve the available treatment for $\mathrm{AF}$ and to test $\mathrm{AF}$ as a risk factor.

The development of new conduction disorders or the need for a permanent pacemaker implantation was not associated with $\mathrm{LoS}$, which is surprising, but might be explained by the low number of events $(n=5 / 114)$.

As many patients suffer from the combination of aortic stenosis and regurgitation, it is difficult to isolate the cause for the significance of the diastolic blood pressure and the trend with patients also suffering from mitral regurgitation. Diastolic blood pressure was negatively associated with LoS and can be associated with an increase in stiffness of the arterial wall in older patients with atherosclerosis or chronic kidney disease. The pathophysiology in relation to the $\operatorname{LoS}$ is interesting and could be part of future research.

The measurements taken from CT angiography (minimal diameters of the left and right iliac arteries) may allow for a reconsideration of equipment used during the procedure. The current generation of Edwards SAPIEN 3 valves can be placed using a $14 \mathrm{Fr}$ catheter, which already has been shown to reduce complications. ${ }^{21}$ Using angiography may give a more precise diameter of the annulus and the iliac arteries, and could be considered to improve accuracy. ${ }^{22}$

\section{Complications}

As predicted, many of the complications correlate significantly with LoS, especially the major complications. The need for transfusions was associated with longer LoS and may reflect a weaker patient status. The influence of the acute kidney injury (stage 1) on LoS shows again the importance of managing kidney function.

In our population, most of the infections were urinary tract infections occurring within 3 days of the procedure; however, there were two cases of infections that occurred after 11 and 29 days. These may have been prevented by an earlier discharge from the hospital.

\section{LIMITATIONS AND FUTURE DIRECTIONS}

Despite the relatively small sample size of this study, it provides insight in the first years of TAVI on a larger scale, allowing future comparisons. Second, to provide optimal care for patients, it is important to find a balance between early and delayed discharge. To better understand the consequences of early discharge, it is important to also take into account rehospitalisation and care provided by (informal) caregivers. A third limitation is the inclusion of Edwards SAPIEN XT valves only. We recommend to include in subsequent studies newer valve types of various manufacturers.

Preprocedural aortic and mitral insufficiencies were not identically assessed excluding the parameters from this study.

\section{CONCLUSIONS}

Prolonged LoS was associated with higher values of STS-PROM and EuroSCORE I. Even so for lower values of eGFR, METs, CT-based right femoral diameter and diastolic blood pressure. Finally, the presence of pre-existing $\mathrm{AF}$ was associated with prolonged $\mathrm{LoS}$ as shown by univariate analysis. After multivariate linear regression METs was the most important variable that remained. METs (estimated with the Duke activity status index) is an easy-to-measure variable in daily clinical practice. Understanding patients' physical functionality can improve logistical planning of hospital stay and selecting patients eligible for early discharge.

Competing interests None declared.

Provenance and peer review Not commissioned; externally peer reviewed.

Data sharing statement Questions regarding data sharing can be adressed to the corresponding author.

Open Access This is an Open Access article distributed in accordance with the Creative Commons Attribution Non Commercial (CC BY-NC 4.0) license, which permits others to distribute, remix, adapt, build upon this work non-commercially, and license their derivative works on different terms, provided the original work is properly cited and the use is non-commercial. See: http://creativecommons.org/ licenses/by-nc/4.0/

(C) Article author(s) (or their employer(s) unless otherwise stated in the text of the article) 2017. All rights reserved. No commercial use is permitted unless otherwise expressly granted.

\section{REFERENCES}

1. Nishimura RA, Otto CM, Bonow RO, et al. AHA/ACC guideline for the management of patients with valvular heart disease: a report of the American College of Cardiology/American Heart Association Task Force on practice guidelines. J Thorac Cardiovasc Surg 2014;2014:e1-e132.

2. Kirtane AJ, Leon MB. The placement of aortic transcatheter valve (PARTNER) trial: clinical trialist perspective. Circulation 2012;125:3229-32.

3. Svensson LG, Blackstone EH, Rajeswaran J, et al; PARTNER Trial Investigators. Comprehensive analysis of mortality among patients undergoing TAVR: results of the PARTNER trial. J Am Coll Cardiol 2014;64:158-68. 
4. Petronio AS, Capranzano P, Barbato E, et al. Current status of transcatheter valve therapy in Europe: results from an EAPCI survey. Eurolntervention 2016;12:890-5.

5. George AJ, Boehme AK, Siegler JE, et al. Hospital-acquired infection underlies poor functional outcome in patients with prolonged length of stay. ISRN Stroke 2013;2013:1-5.

6. Chevreul K, Brunn M, Cadier B, et al; FRANCE Registry Investigators. Cost of transcatheter aortic valve implantation and factors associated with higher hospital stay cost in patients of the FRANCE (FRench aortic national CoreValve and Edwards) registry. Arch Cardiovasc Dis 2013;106:209-19.

7. Siebens K, Miljoen H, Fieuws S, et al. Implementation of the guidelines for the management of patients with chest pain through a critical pathway approach improves length of stay and patient satisfaction but not anxiety. Crit Pathw Cardiol 2010;9:30-4.

8. Webb JG, Pasupati S, Humphries K, et al. Percutaneous transarterial aortic valve replacement in selected high-risk patients with aortic stenosis. Circulation 2007;116:755-63.

9. Wiegerinck EM, Boerlage-van Dijk K, Koch KT, et al. Towards minimally invasiveness: transcatheter aortic valve implantation under local analgesia exclusively. Int J Cardiol 2014;176:1050-2.

10. O'Brien SM, Shahian DM, Filardo G, et al; Society of Thoracic Surgeons Quality Measurement Task Force. The society of thoracic surgeons 2008 cardiac surgery risk models: part 2--isolated valve surgery. Ann Thorac Surg 2009;88:S23-42.

11. Toumpoulis IK, Anagnostopoulos CE, Swistel DG, et al. Does EuroSCORE predict length of stay and specific postoperative complications after cardiac surgery?. Eur J Cardiothorac Surg 2005;27:128-33.

12. Hlatky MA, Boineau RE, Higginbotham MB, et al. A brief selfadministered questionnaire to determine functional capacity (the Duke activity status index). Am J Cardiol 1989;64:651-4.

13. Rockwood K, Song X, MacKnight C, et al. A global clinical measure of fitness and frailty in elderly people. CMAJ 2005;173:489-95
14. Levey AS, Coresh J, Greene T, et al; Chronic Kidney Disease Epidemiology Collaboration. Using standardized serum creatinine values in the modification of diet in renal disease study equation for estimating glomerular filtration rate. Ann Intern Med 2006; 145:247-54.

15. Leon MB, Piazza N, Nikolsky E, et al. Standardized endpoint definitions for transcatheter aortic valve implantation clinical trials: a consensus report from the Valve Academic Research Consortium. $J$ Am Coll Cardiol 2011;57:253-69.

16. Kappetein AP, Head SJ, Généreux P, et al. Updated standardized endpoint definitions for transcatheter aortic valve implantation: the Valve Academic Research Consortium-2 consensus document. Eur Heart J 2012;33:2403-18.

17. Arangalage $D$, Cimadevilla $C$, Alkhoder $S$, et al. Agreement between the new EuroSCORE II, the logistic EuroSCORE and the society of thoracic surgeons score: implications for transcatheter aortic valve implantation. Arch Cardiovasc Dis 2014:107:353-60.

18. Green P, Arnold SV, Cohen DJ, et al. Relation of frailty to outcomes after transcatheter aortic valve replacement (from the PARTNER trial). Am J Cardiol 2015;116:264-9.

19. Stevens LA, Schmid CH, Greene T, et al. Comparative performance of the CKD epidemiology collaboration (CKD-EPI) and the Modification of Diet in Renal Disease (MDRD) study equations for estimating GFR levels above $60 \mathrm{~mL} / \mathrm{min} / 1.73 \mathrm{~m} 2$. Am J Kidney Dis 2010;56:486-95

20. Malaisrie SC, McCarthy PM, McGee EC, et al. Contemporary perioperative results of isolated aortic valve replacement for aortic stenosis. Ann Thorac Surg 2010;89:751-6.

21. Ando T, Briasoulis A, Holmes AA, et al. Sapien 3 versus sapien XT prosthetic valves in transcatheter aortic valve implantation: a metaanalysis. Int J Cardiol 2016;220:472-8.

22. Wiegerinck EM, Marquering HA, Oldenburger NY, et al. Imaging for approach selection of TAVI: assessment of the aorto-iliac tract diameter by computed tomography-angiography versus projection angiography. Int J Cardiovasc Imaging 2014;30:399-405. 